\title{
Symbolic Racism or Self-Interest? Comparing Rural and Urban Worries about Obamacare
}

\author{
Theresa Davidson \\ Samford University, Birmingham, AL, USA \\ Email: tcda vids@samford.edu
}

How to cite this paper: Davidson, $\mathrm{T}$. (2018) Symbolic Racism or Self-Interest? Comparing Rural and Urban Worries about Obamacare. Open Journal of Social Sciences, 6, 210-224. https://doi.org/10.4236/jss.2018.66019

Received: May 5, 2018

Accepted: June 26, 2018

Published: June 29, 2018

Copyright (C) 2018 by author and Scientific Research Publishing Inc. This work is licensed under the Creative Commons Attribution International License (CC BY 4.0).

http://creativecommons.org/licenses/by/4.0/

\section{(c) (i) Open Access}

\begin{abstract}
Framed by the theory of symbolic racism versus self-interest, this study sought to investigate differences, if any, between rural and urban residents' concerns about Obamacare (the Affordable Care Act). First, we found that rural residents are significantly more worried about Obamacare. Second, regarding symbolic racism, ratings of Muslims (but not blacks or immigrants) predicted worry about Obamacare for rural and urban respondents. Third, different self-interest measures were predictive for the rural and urban samples. Rural residents who worried about becoming ill were more worried about Obamacare. Urban residents who worried about money were more worried about Obamacare. We conclude with recommendations for framing health care reform in ways that might reduce concerns among rural and urban people.
\end{abstract}

\section{Keywords}

Public Opinion, Obamacare, Affordable Care Act, Rural, Racism

\section{Introduction}

According to a recent 2017 PEW Research Center Survey, more Americans than ever now support the Affordable Care Act (ACA), the 2010 health care law passed by then President Barack Obama. In April of 2010, just 40 percent of Americans surveyed approved of the law. By February of 2017, however, 54 percent indicated approval and 43 percent indicated disapproval [1]. While many Americans support key components of the law, it has nonetheless been controversial [2].

Researchers have set out to uncover what is behind the controversy and opposition to the Affordable Care Act. While many factors predict opposition to the passage of the health care law including age, gender, and political affiliation [3] [4], an important consideration is the role that self-interest may play in predict- 
ing support or opposition. Indeed, some studies have shown that younger and poorer Americans [5], and women, particularly those on Medicare or Medicaid [6], exhibit stronger support for the ACA. In contradiction, however, some studies have shown that those who may be more in need of the ACA express greater opposition to it [3], or that self-interest plays no role in feelings about the ACA [7]. In light of these contradictions, many researchers have wondered if opposition to the law is due in part to its passage by a black President. Indeed, recent studies have demonstrated a relationship between racial beliefs and opposition to the ACA [8] [9] [10].

This study seeks to address the complex findings on the question of self-interest or symbolic racism regarding health care reform. Importantly, this paper seeks to build on previous public opinion research about the ACA by considering differences in sentiment based on rural or urban residence. At this time, the author is unaware of any other studies that have considered the role of "place" in shaping attitudes toward the ACA. Addressing this gap in the literature is important for two distinct reasons linked to material reality and identity. First, rural places are markedly disadvantaged in terms of access to health care [11] and their residents have poorer health and are less likely to be employer-insured compared to urban residents [12]. This suggests that self-interest should garner support for the ACA. Second, however, the economic and demographic homogeneity [13] and place-based identity rooted in beliefs of independence and self-sufficiency among rural people [14], suggest that resistance to a government-mandated policy devised by a President perceived as "other" might meet resistance. Using a nationally representative dataset, we ask what role "place" plays in shaping attitudes toward the Affordable Care Act by comparing rural and urban attitudes. Additionally, we consider what roles symbolic racism and self-interest play in concerns about the ACA. We hope this study will contribute to a deeper understanding of the role that racial bias may play in shaping public opinion toward social policy. The following sections review the theoretical and empirical literature that frames our questions.

\section{Literature Review}

\subsection{Rural versus Urban}

Since the writings of Tonnies and Durkheim [15], social theorists have considered the role of place in shaping social relations, interactions, and worldviews. Tonnies identified two types of societies: gemeinschaft and gesellschaft. Gemeinschaft describes a community bound together by a series of family and neighborly ties, with shared values, located within a shared location. Gesellschaft identifies "associations" based on formality and contractual agreements, in which relationships are a means to an end. Similarly, Durkheim classified social relationships into two types: mechanical and organic. Mechanical solidarity comprises social relations that involve homogeneity in productive activity, values, and worldviews. Organic solidarity indicates modern, post-industrial rela- 
tions based on dissimilarity yet interdependence.

These frameworks are valuable for characterizing and analyzing the differences between rural and urban places and people. At one end of the continuum (gemeinschaft and mechanical solidarity) are rural people with social networks that are longer-term and more dense [16] and communities characterized by economic and demographic homogeneity [13]. Moreover, these realities are argued to produce a unique place-based identity for rural people who see themselves as distinct from urban people [14]. On the other end of the continuum (gesellschaft and organic solidarity) are urban places and people where relations are based on contractual exchanges, competition rather than cooperation, and populations that are more diverse and geographically mobile [17].

Notably, some researchers have argued that the forces of globalization have made rural places less distinct [18] and that all Americans have been socialized to share a "culture of place" [19], concluding that the differences between rural and urban may be overemphasized. However, attitudinal research continues to show some key differences between rural and urban places on a breadth of topics including the environment [20], immigration [21] [22], and the impact of technology [23]. Consequently, for this project, we pursue the question of rural-urban difference by comparing attitudes toward Obamacare, incorporating symbolic politics and self-interest frameworks to further tease out potential distinctions.

\subsection{Symbolic Racism or Self-Interest}

Symbolic racism [24] argues that individuals acquire prejudiced attitudes through the process of childhood socialization. These biased attitudes tend to be consistent into adulthood and ultimately influence attitudes toward political issues, in particular, issues that appear to have a racial component to them. Thus, prejudice becomes a political force by shaping attitudes toward any policy that may benefit the group that is the subject of one's prejudice. Rather than a reasoned evaluation of the policy or issue, individuals respond based on the symbol of race.

Indeed, a fair amount of research examining the determinants of attitudes toward health care policy has demonstrated that race is a factor. For example, recent studies by Maxwell and Shields [9], and Legerskiand Berg [25], both found that racial attitudes significantly predicted opposition toward health care reform. Two other studies are particularly noteworthy for their approaches. Each compared attitudes toward health care reform when attributed to President Obama, or, former President Clinton. Knowles, Lowery, and Schaumberg [8] and Tesler [10] both found that when the same policy was attributed to Obama, it received much more opposition. Similarly, Banks [26], using a sample of white Americans, found that anger leads racial conservatives to oppose health care reform. Likewise, Suthammanont, Peterson, Owens, and Leighley [27] showed that when individuals felt anxious, they reported less support for racial policies than those 
who did not feel anxious.

On the other hand, the possibility that individuals respond to political issues and policy based on a potential real impact it may have, must be considered [28]. It is entirely possible that symbolic racism is not the only factor that influences political attitudes. In fact, several studies have found that self-interest does play a role in feelings about the ACA. Shue et al's [4] study of Indiana residents found that non-whites-those most likely to need health care coverage-were in favor of health care reform. Sances and Clinton [29] found that the expansion of Medicaid in a state increased support for the ACA among those who were aware of the expansion. Similarly, Gelman et al. [5] showed that younger poorer Americans were the most supportive of health care reform. It should be noted, however, that Gelman's data were from 2000 and 2004, the pre-Obama years. Using more recent data, Hall et al. [6] found that black women, women with lower incomes, and women on Medicare or Medicaid were less likely to disagree with the ACA's passage. Notably, there are some studies that show self-interest has little to no effect on attitudes. For example, Brady and Kessler [3] found that opposition to health care reform begins quite low on the income continuum. Similarly, Lynch and Gollust [30] showed that perceptions about the fairness of inequality were more of an influence than self-interest measures. It is clear that the question of symbolic racism or self-interest is unresolved, particularly regarding rural and urban differences. The following sections review the data and methods used for this project.

\section{Data \& Methods}

To address differences in rural and urban attitudes about the Affordable Care Act, we use national data from the 2014 Chapman Survey of American Fears, Wave 1. The data were collected by GFK (Knowledge Networks) for Chapman University in April 2014. Respondents are non-institutionalized adults at least 18 years of age recruited using random-digit-dialing procedures. The final sample consists of approximately 1572 respondents [31].

\subsection{Dependent Variable}

Our dependent measure is based on the survey question, "Thinking about the federal government in Washington D.C., how worried are you about the Affordable Health Care Act, also called Obamacare?" Response categories were in Likert-scale format including "very worried, worried, somewhat worried, not worried at all". The measure was dummy coded such that "1" represents those who indicated they are "very worried" or "worried", and " 0 " represents those that are "somewhat worried" or "not worried at all".

\subsection{Independent Variable: Rural and Urban}

We include the rural/urban variable as a key variable of interest in our first regression analysis. For our subsequent analyses we divide the sample into rural or 
urban residence to tease out differences in worries about the ACA. This measure is based on the variable "PPMSACAT" from the Chapman Survey which indicates the respondent's MSA (Metropolitan Statistical Area) status. This measure identifies respondents as non-metro (0) and metro (1). We recode such that " 1 " reflects "rural (non-metro)" and "0" reflects "urban (metro)".

We expect rural-urban differences in concern about the ACA. As stated previously, rural populations are less healthy, have more pre-existing conditions, tend to be older, and are less likely to have employer-sponsored health insurance [32]. Indeed, a recent study documents the positive impact that the ACA has already had on rural populations including increasing the number of young adults with health insurance, increasing the number of Medicare "donut hole" beneficiaries, covering children with pre-existing conditions, and other positive outcomes [12]. Despite the salience of these realities, we expect that rural respondents will be more worried about the ACA than their urban counterparts.

\subsection{Independent Variables: Symbolic Racism \& Self-Interest}

Three measures are used to represent symbolic racism. In order to capture racial bias, we use three measures based on a rating scale for three social groups: blacks, immigrants, and Muslims. The rating scale asks respondents "How would you rate the following groups of Americans?" For each group, blacks, immigrants, and Muslims, respondents can choose a number between 1 and 100, with higher scores indicating higher ratings.

Symbolic racism theory argues that learned prejudices are what shape attitudes toward policy. We use measures that capture sentiments about blacks, immigrants, and Muslims for three key reasons. First, despite being mixed-race, President Obama identifies as black [33] and, indeed, is seen as the first black president of the United States. We expect, then, that those who rate blacks lower will worry more about Obamacare because it is associated with a black president. Second, national surveys show that some Americans believe Obama was not born in America. Even after the release of his birth certificate, a 2011 Gallup poll showed that 13 percent of respondents believed he was born elsewhere [34]. As late as 2016, an NBC news poll found that 41 percent of Republicans disagreed with the statement "Obama was born in the US" [35] Thus, we expect that those who rate immigrants lower will worry more about Obamacare. Finally, similar to the views of Obama as a foreign "other"1, many view him as Muslim. A 2009 PEW poll found that 11 percent of Americans believed he was Muslim [36], and a more recent poll [37] found that 29 percent believed the same. Therefore, we expect that those who rate Muslims lower will be more worried about Obamacare.

In order to capture self-interest, three measures are used: employment status, worries about money, and worries about becoming ill. First, roughly half of Americans are insured through their employer [2], so employment status should ${ }^{1}$ For an analysis of the role that nativism, measured by attitudes toward "newcomers" to the US, plays in attitudes toward the ACA, see Knoll and Shewmaker (2015). 
indicate self-interest in health care policy. This measure is dummy coded such that " 1 " indicates respondents who are employed, and " 0 " indicates all other statuses including laid off, looking for work, retired, disabled, or other. We expect that those employed to be less worried about the ACA. Those employed are more likely to have health insurance, thus, will be less worried about health care reform.

Second, we use a measure that captures personal economic instability. This measure asks, "How often do you worry about the following: not having enough money for the future". The response categories are, "almost always, very often, not very often, and hardly ever". These response categories were dummy coded such that "1" reflects those who worry about money for the future "almost always" and "very often", and those who worry "not very often", or "hardly ever" are coded " 0 ". Though the literature is mixed, we expect that those who experience economic vulnerability will be more worried about the ACA.

Finally, another measure capturing health instability asks "How often do you worry about the following: becoming sick". The response categories are, "almost always, very often, not very often, and hardly ever". The response categories were dummy coded such that those who worry about becoming sick "almost always" or "very often" are coded " 1 ". Those who worry "not very often" or "hardly ever" are coded " 0 ". We predict that those with more health vulnerability will be more worried about the ACA. It is likely that even though the most vulnerable may stand to benefit from health care reform, their unstable situations may increase worry and anxiety about a variety of issues, the ACA included.

\subsection{Control Variables}

We also include several sociodemographic control variables. Race is coded such that " 1 " represents white respondents and " 0 " represents non-whites. Education is coded such that "1" reflects those who have a college degree or higher and " 0 " reflects those with less than a college degree. Household income is measured in five categories ranging from "less than $\$ 19,999$ " to “ $\$ 100,000$ or more". Gender is coded so that "1" represents female and " 0 " represents male. Age is a continuous measure. Finally, we control for political ideology. Those who consider themselves extremely conservative, conservative, or leaning conservative are coded as " 1 ", and those who consider themselves moderate, leaning liberal, liberal, or extremely liberal are coded as "0".

\subsection{Analytic Procedures}

We performed four analytic procedures to investigate the relationship between place and worries about Obamacare, incorporating our measures of self-interest and symbolic racism. The first procedure involved performing a difference of means test to compare and describe the rural and urban samples on all key variables. The second procedure involved a logistic regression on worries about Obamacare that incorporated the full sample-both rural and urban respon- 
dents. Finally, a logistic regression was performed separately for the rural sample and then the urban sample, to uncover key determinants within place. The findings are detailed in the following section.

\section{Findings}

\subsection{Rural \& Urban Sample Descriptives}

Table 1 reports the sample statistics for the rural and urban respondents. On our dependent measure, worry about Obamacare, 61 percent of rural residents and 46 percent of urban residents report being worried and this difference is statistically significant ( $\mathrm{p}$-value $=0.000$ ).

Regarding our symbolic politics measures, rural residents rate blacks at about 70 and urban residents rate them slightly lower at just over 68. Rural residents rate immigrants at just under 55 and urban residents rate immigrants at just over 57. The different ratings for blacks and immigrants are not statistically significant. Regarding Muslims, rural respondents rate them at just over 47 and urban respondents rate them at 51 . This difference is approaching significance with a p-value of 0.073 .

In terms of our self-interest variables, 53 percent of rural residents and 57 percent of urban residents are employed, and this difference is not statistically

Table 1. Sample statistics for rural and urban.

\begin{tabular}{|c|c|c|c|c|c|}
\hline Measure & Rural & Urban & Minimum & Maximum & $\begin{array}{l}\text { Significant } \\
\text { Difference }\end{array}$ \\
\hline Worried about Obamacare & 0.61 & 0.46 & 0.00 & 1.0 & $* * *$ \\
\hline \multicolumn{6}{|l|}{ Symbolic Racism } \\
\hline Rating for blacks & 70.22 & 68.61 & 0.0 & 100.0 & \\
\hline Rating for immigrants & 54.83 & 57.52 & 0.0 & 100.0 & \\
\hline Rating for Muslims & 47.32 & 51.01 & 0.0 & 100.0 & + \\
\hline \multicolumn{6}{|l|}{ Self-Interest } \\
\hline Employed & 0.53 & 0.57 & 0.0 & 1.0 & \\
\hline Worry about money & 0.51 & 0.48 & 0.0 & 1.0 & \\
\hline Worry about becoming Ill & 0.33 & 0.28 & 0.0 & 1.0 & + \\
\hline \multicolumn{6}{|l|}{ Controls } \\
\hline White & 0.81 & 0.71 & 0.0 & 1.0 & $* *$ \\
\hline College or more & 0.19 & 0.36 & 0.0 & 1.0 & $* * *$ \\
\hline Family income & 30.05 & 30.52 & 1.0 & 5.0 & $* * *$ \\
\hline Women & 0.53 & 0.49 & 0.0 & 1.0 & \\
\hline Age & 51.64 & 49.98 & 18.0 & 92.0 & \\
\hline Conservative & 0.43 & 0.37 & 0.0 & 1.0 & + \\
\hline$n$ & 269 & 1304 & & & \\
\hline
\end{tabular}

$\mathrm{p}<0.10+, \mathrm{p}<0.05^{*}, \mathrm{p}<0.01^{* *}, \mathrm{p}<0.001^{* * *}$. 
significant. Fifty-one percent of rural respondents and 48 percent of urban respondents report being worried about money. This difference is not statistically significant. Regarding worries about becoming ill, 33 percent of rural, and 28 percent of urban respondent report this concern. This difference approaches significance with a p-value of .081 .

\subsection{Determinants of Worry about Obamacare: Full Sample}

Table 2 presents the findings for the logistic regression predicting attitudes toward Obamacare using the full sample. Regarding our key variable of interest, rural, we find that rural respondents are over one-and-a-half times more likely to be worried about Obamacare than their urban counterparts.

Only one of our symbolic racism measures is predictive of worry about Obamacare: sentiments toward Muslims. Those who rate Muslims higher are less likely to be worried about health care reform. Ratings toward blacks and immigrants show no predictive power.

Two of our three self-interest variables are predictive. While employment status is not related to worry about Obamacare, worries about money and becoming ill are predictive.

Finally, three of our control variables are predictive. Whites are nearly twice as likely as non-whites to worry about Obamacare. College-educated respondents are notably less likely to worry. Those who identify as conservative are

Table 2. Determinants of worry about Obamacare for full sample.

\begin{tabular}{|c|c|c|}
\hline Measure & Odds-Ratio & Standard Error \\
\hline Rural & $1.69^{\star *}$ & 0.17 \\
\hline \multicolumn{3}{|l|}{ Symbolic Racism } \\
\hline Rating for blacks & 1.00 & 0.00 \\
\hline Rating for immigrants & 1.00 & 0.00 \\
\hline Rating for Muslims & $0.99^{* * *}$ & 0.00 \\
\hline \multicolumn{3}{|l|}{ Self-Interest } \\
\hline Employed & 1.01 & 0.14 \\
\hline Worry about money & $1.43^{* *}$ & 0.14 \\
\hline Worry about becoming Ill & $1.54^{\star *}$ & 0.15 \\
\hline \multicolumn{3}{|l|}{ Controls } \\
\hline White & $1.92^{\star * *}$ & 0.14 \\
\hline College or more & $0.71^{*}$ & 0.14 \\
\hline Family income & 1.02 & 0.05 \\
\hline Women & 1.12 & 0.12 \\
\hline Age & 1.00 & 0.00 \\
\hline Conservative & $6.99^{* * *}$ & 0.13 \\
\hline$n$ & 1485 & \\
\hline Nagelkerke $r^{2}$ & 0.33 & \\
\hline
\end{tabular}

$\mathrm{p}<0.05^{*}, \mathrm{p}<0.01^{* *}, \mathrm{p}<0.001^{* * *}$. 
nearly 7 times more likely to be worried about Obamacare than their moderate or liberal counterparts.

\subsection{Determinants of Worry about Obamacare: Rural and Urban Samples}

Table 3 presents the logistic regression findings for the rural and urban models to tease out potential differences in predictors of worry about Obamacare.

Beginning with the rural model and our symbolic racism measures, it is notable that respondents who rate Muslims higher are significantly less likely to worry about Obamacare. Only one of our self-interest measures is significant: rural respondents who worry about becoming ill are nearly 5 times more likely to worry about health care reform than those who are not concerned about becoming ill. For the remainder of our rural model, those with more education are less likely to worry, and those who identify as politically conservative are more likely to worry about Obamacare.

Table 3. Determinants of worry about Obamacare: Rural and urban samples.

\begin{tabular}{|c|c|c|c|c|}
\hline \multirow[t]{2}{*}{ Measure } & \multicolumn{2}{|c|}{ Rural } & \multicolumn{2}{|c|}{ Urban } \\
\hline & Odds-Ratio & S.E. & Odds-Ratio & S.E. \\
\hline \multicolumn{5}{|l|}{ Symbolic Racism } \\
\hline Rating for blacks & 1.00 & 0.01 & 1.00 & 0.00 \\
\hline Rating for immigrants & 1.00 & 0.01 & 1.00 & 0.00 \\
\hline Rating for Muslims & $0.98^{\star \star \star}$ & 0.01 & $0.99^{*}$ & 0.00 \\
\hline \multicolumn{5}{|l|}{ Self-Interest } \\
\hline Employed & 0.89 & 0.36 & 1.04 & 0.15 \\
\hline Worry about money & 1.17 & 0.37 & $1.42^{*}$ & 0.15 \\
\hline Worry about becoming Ill & $4.80^{* * *}$ & 0.15 & 1.29 & 0.16 \\
\hline \multicolumn{5}{|l|}{ Controls } \\
\hline White & 1.81 & 0.42 & $1.91^{\star * *}$ & 0.16 \\
\hline College or more & $0.34^{\star}$ & 0.43 & 0.77 & 0.15 \\
\hline Family income & 1.17 & 0.13 & 1.01 & 0.05 \\
\hline Women & 1.08 & 0.33 & 1.11 & 0.13 \\
\hline Age & 0.99 & 0.01 & 1.00 & 0.05 \\
\hline Conservative & $6.75^{\star \star \star}$ & 0.36 & $6.98^{\star * *}$ & 0.14 \\
\hline$n$ & 251 & & 1234 & \\
\hline Nagelkerke $r^{2}$ & 0.41 & & 0.32 & \\
\hline
\end{tabular}

$\mathrm{p}<0.05^{*}, \mathrm{p}<0.01^{* *}, \mathrm{p}<0.001^{* * *}$.

For the urban respondents and symbolic racism, as with the rural sample, those who rate Muslims higher are less likely to worry about Obamacare. The self-interest measures are where the two samples diverge. Urban respondents who worry about money are nearly one-and-a-half times more likely than their non-worried counterparts to be concerned about Obamacare. Regarding our 
control variables, white urban respondents are significantly more worried about Obamacare than non-white respondents. Similar to rural individuals, those who identify as conservative are notably more worried about health care reform than moderates or liberals.

\section{Discussion \& Conclusions}

The purpose of this project was to investigate potential differences between rural and urban residents in their concerns regarding the Affordable Care Act, or, Obamacare. In light of the theoretical literature discussed, we expected that rural residents would be more worried about Obamacare. Indeed, this hypothesis was supported as 61 percent of rural people, compared to just 46 percent of urban dwellers report being worried. Rural residence was also a significant determinant of Obamacare worries in our logistic regression analysis of the full sample. Thus, we conducted separate rural and urban logistic regressions to cull key differences between the two. Our findings show that both symbolic racism and self-interest play a role in worries about Obamacare.

Framed by symbolic racism and self-interest theories, we found similarities and differences among rural and urban respondents. First, our hypothesis that symbolic racism would increase worries about Obamacare was partially supported in both rural and urban models. Ratings of blacks and immigrants showed no predictive power. Notably, how respondents feel about Muslims significantly predicts concerns about Obamacare. Lower ratings indicate more worry. This is a key finding, in part, for the fact that sentiment regarding blacks was not significant. This is out of line with previous studies showing that anti-black sentiment is salient in feelings about health care reform [8] [9] [10]. However, we feel that our findings do show support for the theory of symbolic racism in regard to anxiety about Muslims.

Knoll and Shewmaker [38] argued that framing techniques used by political elites characterized Obamacare as "un-American" and "foreign", at the same time that Obama himself was often identified as foreign and "other". In their study, nativist views (concerns that foreign culture is a threat to the American way of life) were significantly predictive of opposition toward health care reform. Furthermore, a recent PEW survey showed that Muslims are the lowest rated religious group among Americans [39]. In light of these various findings, it could be that there is a link between the views of Muslims as "other" and Obamacare as an un-American policy. Further research should directly test this possibility. Moreover, the theory of symbolic racism centers on prejudice against blacks. Given the PEW findings on ratings of Muslims, this framework might be expanded to include prejudice against Muslims. It is possible that Muslims have become the latest symbol that provokes suspicion and anxiety in the public imagination. Further research should also directly test the possible link between anti-Muslim sentiment and policy addressing key ethnic, religious, and even social welfare issues. 
Second, we found that self-interest was predictive of worry about Obamacare, but with different predictive factors in the rural and urban models. While employment status showed no significance in either model, concerns about becoming ill was an important factor for rural residents. Those who worried about becoming ill in the future were nearly 5 times more likely than those who weren't worried to be concerned about Obamacare. This is a salient finding given that rural residents are generally older, less healthy, and more in need of affordable health care [32]. While rural residents, particularly those with health concerns, clearly stand to benefit from Obamacare and Medicaid expansion, they are simultaneously more worried about health care reform. This may not be surprising, however, given that worry in one area of life is related to worries and anxieties in other areas of life [40] [41]. Indeed, we feel that this supports the argument for self-interest as a predictor of worry about Obamacare. Rural residents are realistically anxious about their health status and this predicts their concerns about changes in health care policy.

Concerns about illness were not predictive for urban residents, however. Worries about Obamacare related significantly to worries about money. While other studies have shown income to be an important factor in feelings about health care reform [3], we did not find family income to be predictive. Nonetheless, worries about money support the argument for the influence of self-interest, and this finding is in line with studies showing that economic vulnerability predicts sentiments about Obamacare [5] [6]. Unlike previously discussed studies which predicted support or opposition to health care reform, the present study predicts worries. It is possible that respondents could be worried that Obamacare will not go far enough to help them. It is difficult to be certain how survey respondents interpret the term "worry". However, we feel it is more likely that, as with illness worries, money worries are related to other types of worry, include looming health care changes.

It is also important to note that conservative political views are the strongest predictors of worry in both rural and urban areas. This finding is directly in line with other studies showing conservative political ideology predicts opposition to reform [4] [7]. These findings suggest that it may be reasonable to interpret "worry" as a negative sentiment toward Obamacare in this study.

In conclusion, these findings suggest that different approaches might be taken to inform the public about the Affordable Care Act and its impact in rural and urban areas. Indeed, studies have shown that when the public is better informed about health care reform, they tend to be more supportive of it [4] [29]. Given the unique challenges rural areas face regarding access to, and need for, health care, local news media and health care providers could play a key role in providing more information to their rural residents. Rural information campaigns could focus efforts on the most vulnerable, such as the sick and elderly, to reassure them of the specific benefits of the ACA. In urban areas, the same could be targeted at low- and moderate-income populations as these are the most likely to feel economically vulnerable. Information could be disseminated about the fi- 
nancial benefits of health care reform, and also, the subsidies provided that can help individuals purchase health care ${ }^{2}$. These approaches can speak to our findings here about the influence of self-interest on worries about Obamacare.

In light of the relationship between attitudes toward Muslims and worry about Obamacare, "framing" [38] techniques could be used to market health care reform as a decidedly "American" policy. Public service announcements and social media sites could be useful for appealing to values that resonate with the American public. For example, the Affordable Care Act could be framed as a route to self-sufficiency and independence when it comes to one's health and well-being. A longer-term goal would be to combat prejudice, fear, and stereotypes about Muslims. To that end, community leaders, including religious leaders, could work together to facilitate inter-religious interaction in a variety of social settings. News media could highlight important contributions Muslim Americans make to their local communities. Religious non-profits and volunteer organizations could coordinate inter-religious groups in their various charitable efforts. All of these efforts could facilitate intergroup contact, challenge stereotypes, and break down fear of the "other" [42]. These approaches should address our findings regarding the power of symbolic racism to shape Obamacare worries.

Overall, this study contributes to a literature that is deficient in its consideration of rural-urban differences regarding the public's concerns about health care policy. When changes are made to health care policy, it is imperative that differences between rural and urban populations be considered. We found partial support for both symbolic racism and self-interest in shaping concerns among rural and urban residents. We hope that this study can extend our understanding of the power of symbolic racism to shape policy preferences, and, inform policy makers of ways to address and assuage real public anxieties about health care changes.

\section{References}

[1] PEW Research Center (2017) Political Survey. PEW Research Center, Washington DC.

[2] Kaiser Family Foundation (2011) Kaiser Health Tracking Poll, November. http://www.kff.org/health-reform/poll-finding/kaiser-health-tracking-poll-novembe $\underline{\mathrm{r}-2011 /}$

[3] Brady, D. and Kessler, D. (2010) Who Supports Health Reform? Political Science \& Politics, 43, 1-6. https://doi.org/10.1017/S1049096510990720

[4] Shue, C., McGeary, K., Reid, I., Khubchandani, J. and Fan. (2014) Health Care Reform: Understanding Individuals' Attitudes and Information Sources. BioMed Research International, 2014, Article ID: 813851.

https://doi.org/10.1155/2014/813851

[5] Gelman, A., Lee, D. and Ghitza, Y. (2010) Public Opinion on Health Care Reform. The Forum, 8, 1-14. https://doi.org/10.2202/1540-8884.1355

[6] Hall, K., Nadella, S.P., Zochowski, M., Patel, D. and Dalton, V. (2015) Social, Re${ }^{2}$ At the time of this writing the American Health Care Act under the Trump administration is currently pending in the Senate. Thus, some of these recommendations could change depending upon the outcome. 
productive, and Attitudinal Factors Associated with U.S. Women's Disagreement with the Passage of the Affordable Care Act. Journal of Women's Health, 24, 730-739. https://doi.org/10.1089/jwh.2014.5175

[7] Brodie, M., Deane, C. and Cho, S. (2011) Report from the States: Regional Variations in Public Opinion on the Affordable Care Act. Journal of Health Politics, Policy and Law, 36, 1097-1103. https://doi.org/10.1215/03616878-1460587

[8] Knowles, E.D., Lowery, B.S. and Schaumberg, R. (2009) Racial Prejudice Predicts Opposition to Obama and His Health Care Reform Plan. Journal of Experimental Social Psychology, 46, 420-423. https://doi.org/10.1016/j.jesp.2009.10.011

[9] Maxwell, A. and Shields, T. (2014) The Fate of Obamacare: Racial Resentment, Ethnocentrism and Attitudes about Healthcare Reform. Race and Social Problems, 6, 293-304. https://doi.org/10.1007/s12552-014-9130-5

[10] Tesler, M. (2012) The Spillover of Racialization into Health Care: How President Obama Polarized Public Opinion by Racial Attitudes and Race. American Journal of Political Science, 56, 690-704. https://doi.org/10.1111/j.1540-5907.2011.00577.x

[11] Stanford Medicine (2010) Healthcare Disparities \& Barriers to Healthcare. Fact Sheet.

http://ruralhealth.stanford.edu/health-pros/factsheets/downloads/rural_fact_sheet_ 5.pdf

[12] Bailey, J. (2012) The Affordable Care Act: Real Help for Real Rural People. Center for Rural Affairs.

[13] Tickamyer, A.R. and Duncan, C. (1990) Poverty and Opportunity Structure in Rural America. Annual Review of Sociology, 16, 67-86. https://doi.org/10.1146/annurev.so.16.080190.000435

[14] Bell, M.M. (1992) The Fruit of Difference: The Rural-Urban Continuum as a System of Identity. Rural Sociology, 57, 65-82. https://doi.org/10.1111/j.1549-0831.1992.tb00457.x

[15] Fletcher, R. (1971) The Making of Sociology: A Study of Sociological Theory. Charles Scribner's Sons, New York.

[16] Beggs, J., Haines, V. and Hurlbert, J. (1996) Revisiting the Rural-Urban Contrast: Personal Networks in Nonmetropolitan and Metropolitan Settings. Rural Sociology, 61, 306-325. https://doi.org/10.1111/j.1549-0831.1996.tb00622.x

[17] Bonner, K. (1998) Reflexivity, Sociology, and the Rural-Urban Distinction in Marx, Tonnies, and Weber. The Canadian Review of Sociology and Anthropology, 35, 165-181. https://doi.org/10.1111/j.1755-618X.1998.tb00227.x

[18] Albrecht, D.E. and Albrecht, C.M. (2004) Metro/Nonmetro Residence, Nonmarital Conception, and Conception Outcomes. Rural Sociology, 69, 430-452. https://doi.org/10.1526/0036011041730482

[19] Tittle, C.R. and Grasmick, H.G. (2001) Urbanity: Influences of Urbanness, Structure, and Culture. Social Science Research, 30, 313-335. https://doi.org/10.1006/ssre.2001.0700

[20] Berenguer, J., Corraliza, J. and Martin, R. (2005) Rural-Urban Differences in Environment Concern, Attitudes and Actions. European Journal of Psychological Assessment, 21, 128-138. https://doi.org/10.1027/1015-5759.21.2.128

[21] Fennelly, K. and Federico, C. (2008) Rural Residence as a Determinant of Attitudes toward U.S. Immigration Policy. International Migration, 46, 151-190. https://doi.org/10.1111/j.1468-2435.2008.00440.x

[22] Garcia, C. and Davidson, T. (2013) Are Rural People more Anti-Immigrant than 
Urban People? A Comparison of Attitudes toward Immigration in the United States. Journal of Rural Social Sciences, 28, 118-140.

[23] Sarfo, F.K., Amartei, A.M., Adentwi, K.I. and Brefo, C. (2011) Technology and Gender Equity: Rural and Urban Students' Attitudes towards Information and Communication Technology. Journal of Media \& Communication Studies, 3, 221-230.

[24] Kinder, D.R. and Sears, D.O. (1981) Prejudice and Politics: Symbolic Racism versus Racial Threats to the Good Life. Journal of Personality \& Social Psychology, 40, 414-431. https://doi.org/10.1037/0022-3514.40.3.414

[25] Legerski, E.M. and Berg, J.A. (2014) Americans' Approval of the 2010 Affordable Care Act: Self-Interest and Symbolic Politics. Sociological Inquiry, 85, 285-300.

[26] Banks, A.J. (2014) The Public's Anger: White Racial Attitudes and Opinions toward Health Care Reform. Political Behavior, 36, 493-514. https://doi.org/10.1007/s11109-013-9251-3

[27] Suthammanont, C., Peterson, D.A., Owens, C.T. and Leighley, J.E. (2010) Taking Threat Seriously: Prejudice, Principle, and Attitudes toward Racial Policies. Political Behavior, 32, 231-253. https://doi.org/10.1007/s11109-009-9102-4

[28] Sears, D.O., Lau, R.R., Tyler, T.R. and Allen, H.M. (1980) Self-Interest vs. Symbolic Politics in Policy Attitudes and Presidential Voting. The American Political Science Review, 74, 670-684. https://doi.org/10.2307/1958149

[29] Sances, M.W. and Clinton, J.D. (2017) New Policy, New Politics? The Effect of Medicaid Expansion on Public Support for the Affordable Care Act. Yale University: Center for the Study of American Politics, New Haven.

[30] Lynch, J. and Gollust, S.E. (2010) Playing Fair: Fairness Beliefs and Health Policy Preferences in the United States. Journal of Health Politics, Policy, and Law, 35, 849-887. https://doi.org/10.1215/03616878-2010-032

[31] Chapman University (2014) The Chapman University Survey of American Fears, Wave 1. Earl Babbie Research Center, Orange.

[32] Bailey, J. (2010) Health Care Reform, What's in It? Rural Individuals and Families. Center for Rural Affairs.

[33] Roberts, R. and Baker, P. (2010) Asked to Declare his Race, Obama Identifies as 'Black'. New York Times, April 2.

[34] Jones, J. and Saad, L. (2011) Gallup Poll Social Series: Values and Beliefs. Gallup News Organization.

[35] Clinton, J. and Roush, C. (2016) Poll: Persistent Divide over "Birther" Question. NBC News, August 10.

https://www.nbcnews.com/politics/2016-election/poll-persistent-partisan-divide-ov er-birther-question-n627446

[36] PEW Research Center (2009) No Decline in Belief That Obama Is a Muslim, April.

[37] CNN/ORC International (2015) Poll. September 4-8.

[38] Knoll, B.R. and Shewmaker, J. (2015) 'Simply un-American': Nativism and Support for Health Care Reform. Political Behavior, 37, 87-108. https://doi.org/10.1007/s11109-013-9263-Z

[39] PEW Research Center (2014) How Americans Feel about Religious Groups.

[40] Dar, K.A. and Iqbal, N. (2015) Worry and Rumination in Generalized Anxiety Disorder and Obsessive Compulsive Disorder. The Journal of Psychology, 149, 866-880. https://doi.org/10.1080/00223980.2014.986430 
[41] Eysenck, M.W. and Van Berkum, J. (1992) Trait Anxiety, Defensiveness, and the Structure of Worry. Personality \& Individual Differences, 13, 1285-1290. https://doi.org/10.1016/0191-8869(92)90170-T

[42] Allport, G. (1954) The Nature of Prejudice. Perseus Books, Cambridge. 